\title{
Stylistic Analysis of English Advertising Language*
}

\author{
Wei Zhou \\ Harbin Engineering University \\ Harbin, China
}

\begin{abstract}
With the rapid development of the economy and our society, advertisements are more and more popular with people's lives. In fact, advertisements played a major role in branding products and attracting customers, as well as leading people know the features of products. The paper introduces characteristics of advertising language and analyzes its stylistic features from the three perspectives of vocabulary, syntax and rhetoric. This paper adopts qualitative analysis of examples taken from websites and magazines. This paper concludes that English advertising language is different from formal English in word use, and through using simple, interrogative and imperative sentences, it has a distinct language style that is concise, attracting and can help business people sell their products. In addition, English advertising language owns a dramatic way of expression due to the wide use of various kinds of rhetoric, which makes advertisements catchy and readable.
\end{abstract}

Keywords-advertisement; stylistic features; lexicology; syntax; rhetoric

\section{INTRODUCTION}

\section{A. Background}

Research has found that advertising is a mean to seize market, and its effect is to "set up the product image, convey information, stimulate consumption, and persuade people to buy products, etc." (Wan, 178). In order to attract consumers, many advertisers write vivid advertisement slogans in different ways, so as to expand and deepen the advertising influence as well as strengthen advertising power into full play. They use various linguistic devices to catch attention, arouse desire, induce action, and contribute to satisfaction. It is just an art of language using various kinds of devices. The advertisements have achieved amazing effects on persuading consumers to buy the products. At the same time, it has also formed its special style and the language used in advertisements is different from other styles. Its function is to "attract attention, arouse interest, stimulate desire, create conviction and get action (Yang 102)." It is a kind of loaded language with persuasive power. Advertisements are noveldesigned, concise and colorful which are full of aesthetics and can be fast read in order to attract people's attention as much as possible, and arouse readers' strong purchasing desire and persuade them to purchase the products.

Also, during the process of globalization and

*This paper was supported by Humanities and Social Science project in Heilongjiang Province (Grant No. 12544042), Fundamental Research Funds for the Central Universities (Grant No. HEUCF181205) industrialization, an increasing number of products are produced in the world every day. As a result, advertisement plays a major role in selling products. In order to secure a number of readers and to compete with many other similar advertising messages, advertisers try to make their advertisements as helpful as possible. With China's entry into the WTO, understanding the role of different types of sentences in English advertising words can purposefully guide advertising language and put new energy into social and economic life in a planned way.

So this paper intends to analyze English advertisements from the aspects of their lexical, syntactic and rhetorical features, and find out the effects that brought about by these stylistic features.

\section{B. Literature Review}

Professors in areas about language or linguists attached great importance to English advertisements and made their researches on the stylistic features of language in English advertising language. Plenty of linguists have made researches on the topic, of which Geoffrey N. Leech (293301) did basic research in the aspect with his book English in Advertising, which provided us with a detailed analysis of the linguistic devices employed by advertisers, especially the grammatical and lexical features. He found that metaphors are widely used in advertising language. In 1982, Lakoff analyzed discourse in television advertising language, and founded an essential feature which takes advantage of novel terms and expressions (488-507). He also identified two types of syntactic innovations in television advertising: the absence of subjects and verbal auxiliaries, an odd use of the definite article.

Further research on advertising language involves the context in advertising discourse, which an increasing number of scholars has paid attention to. Guy Cook is one of its forerunners, who gave a detailed description of linguistic devices used in a specific context and of the effect of pictures and sounds in the advertisement. Then in 1997, Goatly Andrew studied on metaphors used in English advertisement (53), which made further analysis in rhetoric. Wang Hongxin also analyzed the figure of speech of the advertisement, involving the personification, pun, simile, metaphor, etc in certain advertisements, and her thesis was a comprehensive stylistic analysis of the time (81-83).

Based on the former studies, the paper uses qualitative research to clarify main stylistic characters of English advertising language. To analyze the typical instances of 
each aspect, the author chooses the method of analysis and classification in the process of determining these features in order to analyze those advertisements. Also, to choose some typical characters in this paper, the author utilizes comprehensive and induction after material collection.

\section{StYLISTIC FEATURES OF ENGLISH ADVERTISEMENTS}

\section{A. Lexical Characteristics}

The aim of English advertisement is to make consumers understand the products and attract more people to buy goods. So extensive use of single syllable words in English advertisements, together with short and simple word structure, can accurately convey commodity information. At the same time, in order to make the advertisement close to life and easy to be remembered, people also use a large number of simple adjectives and personal pronouns in English advertisements.

1) Refining verbs: Verbs used in English advertising language are relatively less than other words, and usually they are "common" or "ordinary" words in people's daily life (Zhang, 13). The effect of using these verbs includes simplifying the expression and making advertisements more understandable, so that they are not difficult to remember, such as: make, get, feel, give, have, see, buy, know, look, taste, take, start and choose, etc.

These words are basically monosyllabic words, and they constitute the core part of the English vocabulary, which English-speaking people often use for relatively stable meanings of these words and phrases. In English advertisements, these simple words can win more consumers because they are capable of expressing accurately and effectively as well as a sense of intimacy. For instance:

\section{"Enjoy coca-cola." (Coca-cola, America)}

"Make your-self heard." (Ericsson, Sweden)

In the first example, the advertiser uses the simple word "enjoy" instead of a series of sentences describing how nice the drink is, but it still successfully wins hearts of consumers. "Enjoy" has the meaning of appreciation, and the things that people enjoy are always satisfactory and wonderful, so when people read advertisement like that, they are curious enough to buy and taste the drink. While in the second example, the verb "make" is also simple and powerful, which just shows that the phone can carry the duty of communication. As a result, advertisements like these can always attract people's attention. In English advertisements, too many long or complex verbs are unnecessary, and on the contrary, when advertisers try to refine the verbs, they can achieve more effect, like creating humor and attracting attention.

2) Using simple adjectives: As words that are rich in the expression of emotion, adjectives are widely used in English advertising language. In fact, descriptive and evaluative adjectives or the comparative and superlative degree of adjectives are the main part of the adjectives appeared in English advertisements. Using adjectives, products can get great beautification, to which the attention of consumers can also be effectively appealed. Such adjectives are as follows: good/better/best, rich, full, nice, clean, fresh, real, great, big, forever, fine, and so on. These adjectives can convince the customer that choosing these products or services could make their lives better. The use of comparative and superlative adjectives can highlight the advantages and characteristics of the goods or services. For example, "Feel the new space." (Samsung, Korea)

In this example, the advertiser just shows people an advanced and high-tech product through introducing a "new space" to customers. "New" means having just come into being or been made or acquired or discovered, which might not be found until now. People know that they all live in a known space which is called the real world. But what about a "new" world? What a different space can be like? A simple adjective enables customers to imagine what Samsung will do to improve their life, thus becoming concentrated in Samsung products.

Another example is made by Nescafe, with its "The taste is great". While people always say "great" towards the things they satisfy with, using this word in the advertisement can indicate that the coffee owns peculiar flavor and excellent quality.

3) Using compound words: English advertisements especially advertisements of technical equipment contain a large number of compounds, and most of them are compound adjectives. Since technology and equipment are relatively complex, the introduction of the compound words can simplify the instructions of the equipment and accurately describe one of the functions or characteristics of the equipment. Also, instead of using too many clauses, the use of the compound words can make the advertisement easier to read and understand, such as high-tech, full-color, multi-functional, water-prevent, etc.

What's more, compound words, except in news writing, are rare in other literary forms. In advertising, advertisers tend to use compound, for they can not only save a much space, but often break the routine to be unique in style, make advertising language more dramatic, strengthen the function of improving memory and attention, and leave more enduring profound effect in the audience hearts as well. For example:

"From a heavy-weight, comes the latest light-weight." This is Sony's advertisement for its new ear phone. When using ear phones, people usually tend to choose those that have a tiny size and are easy to be put into a bag. Sony catches this point and develops its slogan with two opposite compounds, which highlights a distinct feature of its new product.

From another point of view, these compound words in advertising language is usually used as the front modifiers, the description of the nature of the products can always win more focus, let consumers psychologically, easier to accept, and can enhance the function of persuasion in advertising language. 
4) Using personal pronoun: Personal pronouns often appear in English advertisements, in which the use of the first person "I and we" as well as the second person "you and your" are far more than that of other pronouns. The use of the first and second personal pronouns can shorten the distance between consumers and businesses and provide people with a friendly atmosphere, which can also prompt consumers' desire to buy this product or to pay for this service. Here are some typical advertisements:

"We lead, others copy." (Ricoh, Japan)

"We integrate, you communicate." (Mitsubishi, Japan)

"Obey your thirst." (Sprite, America)

In those sentences, advertisers use such personal pronouns as "we" and "you" to let people feel as if they are making a conversation with each other, which is similar to friends' talk or daily communication. Under such mood, customers would create a sense of intimacy, thus being more likely to choose the product. In Ricoh's slogan, the word "we" shows a sense of pride, while in the second example, Mitsubishi makes people know that the product is produced to improve people's life. All these personal pronouns are trying to gain customers' attraction through acting as a person in their actual life and persuading them to choose the product. And in the three cases above or more, advertisements have achieved their goal.

\section{B. Syntactic Features}

In English advertisements, if advertisers make proper use of sentence structure and tone, they can highlight the features of products or characteristics, functions and advantages of the advertising projects, thus make them more competitive.

1) Short and simple sentences: Advertising language should inspire the reader's purchase desire as effectively as possible with the least amount of space, the most refined language to convey the most information. Thus, advertising English tries to use short sentences, simple sentences, and avoid using complex sentences. Among sentences of English advertising language, most of them are short and simple sentences. Just because advertisements are written for the mass, the sentence structure of the advertising language should be concise and vivid, which can quickly grasp the public's attention. At the same time, long sentences are shortened in order to reduce the psychological burden on advertising language comprehension and to enhance its readability. As a result, compared with complex sentence structure, advertisers more commonly use a short sentence structure. For instance:

"Fresh-up with seven-up." (7-up, America)

“Apple think different." (Apple, America)

"Impossible made possible." (Canon, Japan)

All these slogans are short and simple sentences, but just because they are brief in structure, they are more likely to come into consumers' eyes and are easier to remember.
2) Elliptical sentences: Another obvious feature of English advertising is the wide use of ellipsis sentences. On the one hand, since the space of advertisement is limited, advertisers have to simplify the minor parts of the sentence or delete some unnecessary words. On the other hand, since an elliptical sentence can be bright, outstanding, compact and eye-catching, it can "effectively change the rhythm of the prose, easily create visual and psychological dislocation of listeners and readers, and attract their attention"(Zhang 13). So, using elliptical sentence in advertising language can also incite customers to buy the product.

Here is one example: "Communication unlimited."(Motorola, America) In this slogan, both the verb and object are omitted, and only the adjective "unlimited" is left to modify the subject. But this short advertisement that makes up of just two words has provided consumers with the most helpful information, that the mobile phone can let people realize smooth and fast connection with each other. Without listing a series of useless words or phrases, an elliptical sentence can let people quickly learn what feature the product has.

3) Interrogative sentences: In order to enhance its function of attention and memory value, advertisements also use interrogative sentences a lot. Question is easy to arouse people's reactions, especially using it in the subject line or the body of the advertising at the beginning. This can stimulate the curiosity of reader's psychology and increase their interest in reading. As the following butter advertisement by Lurpark:

What's so special about Lurpark Danisb butter? Well, can you remember what butter used to taste like-real fresh from house butter? Do you remember how you used to enjoy it when you were young? Today, the taste of Lurpark bring it all back to you -that's why it's so special.

The advertisement use interrogative sentences many times. It is from the first sentence "What's so special about it" to start asking questions, and continue itself ring by ring, grabbing the reader's psychology and highlighting the characteristics of its butter. If the advertiser uses statements, the whole statement will be too bland, even boring. Attracting customers with question sentences is a traditional manner now. Whether it is a general question, antisense question or special question, it can have certain euphemistic function. At the same time, the question can also prompt listeners or readers to think, make the echoes and can inspire their curiosity as well as gain a psychological sense of excitement.

4) Imperative sentences: The fundamental purpose of advertising is to encourage listeners or readers get psychological resonate, and then take action, so it try to make full use of the daily language or loaded language to enhance the persuasion and inducing power. The ordering sentence itself has the function to request, call or advise people to take action, and therefore is widely used for advertising. 
For example, Canada health company Habitrol writes its smoking cessation slogans as: "Add power to your will" and "Double your chance of quitting", which aim at calling for people to give up smoking by persuasive language. Other examples about imperative sentences have the same function as well: "Hold it and you are hooked" (Ericsson), "Start ahead" (Rejoice) and "Focus on life." (Olympus)

Imperative sentences in the English advertisements are countless in a degree. Compared with the corresponding statements, such ordering sentence is more encouraging and persuading. Advertisers naturally think that the public is used to accept for their advice, encouragement and instruction, so they use a mass number of ordering sentences. As a result, the tone of advertising becomes coherent and tempted, and the advertisement can successfully achieve the goal of persuasion .

\section{Rhetorical Features of English Advertisements}

As a way of passing information to the general consumers, advertising English is often used in a variety of rhetorical devices to increase the sense of beauty and rhythm, as well as to attract the masses, so as to achieve the aim of market development and marketing products. Advertising English is a commercial art. Add appropriate figures of speech in advertising, can make the advertisement reads catchy, full of rhythm and rhyme wonderfully, thus increase the vivid, cordiality and novelty characters of English advertisements.

1) Pun: The English word pun comes from the Latin word "paronomasia", its original intention is to "use different names to call". Its fundamental feature is fuzzy expression and double meanings, which means in a specific context, a word, phrase or sentence has two ways of explanation, thus create a sense of humor and stimulate people to think. Pun is a common figure of speech, especially in advertising language. With pun, people can express two meanings in a specific context in a language form . The use of this rhetoric is not only to describe the feature of products, but can also transfer the intention and purpose of the advertisers, and in this way can it stimulate consumers' purchasing desire.

Pun lets readers make an unavoidable a smile at the same time they read the slogan, and leave deep impression in their minds. For example:

"From sharp minds, come sharp products." (Sharp, Japan)

This is a slogan from Sharp, in which the word "sharp" means both quick-minded and the idea of Sharp company. Intel's advertisement is another excellent example: "Intel inside." (Intel, America) It also combines a real product with the spirit of company, which not only introduces the idea of Intel company, but also shows the great power of Intel CPU.

2) Parallelism: Parallelism is the structure that means "giving two or more parts of one or more sentences a similar form to create a definite pattern." The use of parallelism can strengthen the mood of language, highlight the features of the goods and strengthen the effect of advertising.
Putting parallel structure in English advertising slogans can help advertisers protrude the distinguishing features of the product or service, and make it more visual and specific. For instance: "Buy it. Sell it. Love it." it is a slogan of PayPal website. The advertisement clearly presents PayPal's feature that people can auction or shop online through using such short parallel sentences like this. A longer one made by Christchurch Canterbury is also equipped with this power: "St. Augustine founded it. Becket died for it. Chaucer wrote about it. Cromwell shot at it. Hitler bombed it. Time is destroying it. Will you save it." Through parallelism, the advertisement lists different actions of different people to show others the history of Christchurch Canterbury.

3) Repetition: In English advertisements, to emphasize a certain characteristics of goods, an advertiser often deliberately repeats some certain words or sentences, so that readers can keep the information that the advertiser want to emphasis in mind. Repetition means when speaking or writing articles, people often consciously repeat some certain content. It can be a word, a sentence, and sometimes even a rhetorical device. It usually has three functions. First, it can strengthen the rhythm and highlight the rhyme beauty of advertisements. It also deepens the semantics and strengthen the effect that advertisers want to express. In addition, it connects the passage, which improves the fluency of sentences. For instance, the slogan "Extra taste, no extra calories"(Riviana Foods, America) is of the second category, in which the advertiser strengthens that there is no fat in the food so that people can enjoy it.

Using repeated rhetoric properly cannot only obtain certain rhetorical effect, and can make the advertising English be stressed that is easier to give consumers a powerful momentum, strengthen product publicity, and let people become unforgettable towards the product. In other words, it can let consumers buy their goods or create an idea of purchasing.

4) Metaphor: The use of metaphor can make the content that advertiser want to express easy to understand, and describe things vividly and specifically. Using metaphors can make the features and benefits of the product vividly showed in the sight of the reader, and can leave a deep impression to them.

Like simile, metaphor is to make comparison between two objects that belong to different categories. However, the difference is, simile means that the noumenon and metaphorical object is similar, while metaphor simply says that both sides are consistent, and metaphor does not use analogy words. Metaphor skillfully imply things that people are not familiar with, or are not easy to grasp through an image, character, action or philosophy which are familiar to people. So the advertisement slogan tends to be more concise, appropriate, vivid and subtle. Such as:

"All of New York is a stage." (The Metropolitan Opera House, America)

This advertisement uses the rhetoric of metaphor, in which New York is compared to a stage. When people read 
it, they would see it as if watching the tragicomedy of the busy, luxuriant and bustling New York that shows in three hundred and sixty-five days all the year.

\section{CONCLUSION}

The paper has introduced advertising language and analyzed its stylistic features in three aspects of lexical, syntax and rhetoric. From the above analysis of stylistic features of English advertising language, the conclusions are as follows:

First, formal English and English advertisements have a distinct style of characteristics. Advertisements, as informal English slogans, are made up of words that are concise and easy to understand. Also, the sentence structure is simple and catchy to read. But formal English does not possess these stylistic features. Therefore, for English learners who mainly study formal English, analysis of characteristics of English advertising style will help them further understand the English language as well as British and American culture.

Second, with regard to business, analysis of stylistic characteristics of English advertising language, particularly the successful ones, can help business people clarify the demand of customers. From the above analysis, it is easy to see that those advertisements which do well in attracting the customers have a similar language style: they mostly use short and elliptical sentences to make the advertisements concise and let people easily focus on them through interrogative and imperative sentences. So making full use of such an analysis in their advertisements, business people are more advantageous to the sale of products.

Third, various figures of speech that the English advertising language used and the variety of features in the aspect of word choice and sentence pattern selection show that advertising language has some dramatic characteristics in its form. Typically, with rhetoric such as pun and repetition, the advertisements are catchy and full of readability. It has changed the character of advertising language, which used to be simple and predominantly persuasive, into the characters of literature language, and let advertisements gradually become a new kind of popular literary form.

In making collection of the linguistic data of English advertisements, since the author's personal ability is limited, the analysis in this paper may be one-sided, and the paper lacks negative proof. What is more, because stylistic features of English advertising language are very extensive and due to the limitation of space, in each aspect this article has only selected four comparatively typical features to analyze, which may not be so comprehensive. If further research is possible, the author will make every effort to improve this paper with more examples and analysis.

\section{REFERENCES}

[1] Cook, Guy. The Discourse of Advertising. London: Routledge, 2001.Print.

[2] G. N, Leech. English in Advertising, London: Longman,1966. Print.
[3] Goatly, Andrew. "Metaphor and ideology."Ilha do Desterro, 2011.Print.

[4] Lakoff, George. Metaphors We Live By. University of Chicago Press, 2003. Print.

[5] Gu Xitao. Study of English advertisement from the perspective of stylistics. [D] Hebei Normal University, 2003.

[6] Huang yimin. Research on modern English advertising. [D] Fudan University, 2001

[7] Lei Wen. On the phenomenon of adjectives in classical Chinese English advertising slogans. [J]. Journal of Changzhou Institute of Technology ((Social Science) 2014(5): 94-98.

[8] Wan Xue. An analysis of the characteristics of English advertising language. [J] The Science Education Article Collects, 2008(17): 178179.

[9] Wang Hongxin. An example analysis of the application of rhetorical figures in English Advertisements. [J] Journal of Liaoning University of Technology (Social Science) 2004,6(1): 81-83.

[10] Yang Xiasha. Research on the features and translation of advertising language of fashion products. $[\mathrm{J}]$. Science and education guide Electronic Edition (middle), 2013,(7):102.

[11] Zhang Mei. A linguistics analysis of the stylistic features of English advertising slogans. [J]. Reading and writing,2015,(24): 13,16. 